\title{
Deliberate Communication with Pictures: A Science Fiction? ${ }^{+}$
}

\author{
Stuart Medley \\ School of Arts and Humanities, Edith Cowan University, Mount Lawley, WA 6050, Australia; \\ s.medley@ecu.edu.au \\ + Presented at the International and Interdisciplinary Conference IMMAGINI? Image and Imagination \\ between Representation, Communication, Education and Psychology, Brixen, Italy, 27-28 November 2017. \\ Published: 27 March 2018
}

\begin{abstract}
There are assumptions about images and how these compare with words, in terms of what is afforded us in communicating with each other. These assumptions have been limited by religion and economic imperatives in the past, and by education systems that grew out of those vested interests. One way to push past these assumptions might be to imagine a world without writing. Some science fiction examples are examined for their feasibility. In addition, the reader is reminded of humanity's pre-writing past, and that pictures that survived from then are viewed through our present contextual lenses as containing a child-like view of the universe. This view has not been helped in western history by hundreds of years of monotheism and its vested interest in framing earlier belief systems as perverse. The origins of writing however, were completely bound up with accounting for production, for tax collecting and distribution, with specialization into occupations: the beginnings of the organized state. Could a future of pictures-only give us the deliberate communication we'd need for these exchanges or is that also science fiction? The major assumption to overcome is that the dependability of words anchors the waywardness of pictures. This paper shows some quotidian examples of picture-only communications which do not invite ambiguous or vague interpretations, and examples are given where pictures can disambiguate words. The future is most likely to witness the further compression of writing, not its total eradication; it is likely that the co-presence of writing and pictures makes for clearest communication. How would communicators be trained to be productive members of such a world? Research into style, pattern recognition and comprehension are necessary to further break down the historical assumptions about what constitutes good depiction. We need to break the spell of visual realism; to see it as only one of many choices for capturing the image, and to see the schema that make pictures up as components that can be taken apart and reassembled. The paper concludes with some examples of science-fiction curricula given to design students to broaden their thinking about the future potential for visual communications.
\end{abstract}

Keywords: visual communication; visual realism; future; science-fiction

\section{Introduction: Writing in Flames}

In academia and education in general there are assumptions about images and how these compare with words, in terms of what is afforded us in communicating with each other. But these assumptions have been limited, by vested interests such as religion and economic imperatives in the past, and by education systems that grew out of those vested interests. As Katya Sander (2012) observes, "Western cultures share a tradition of subordinating images to the textual, of lending the textual an authority over pictures" [1]. One way to push past these assumptions about the affordances of images in visual communication might be to try to imagine a world without writing. 
Figure 1 shows a scene from François Truffaut's film version of Ray Bradbury's science fiction novella, Fahrenheit 451 [2,3]. The film depicts a future where books and writing are banned because they make people think too deeply, and that leads only to misery. If we believe, as we're told, that we live in an in an age inundated with images, this film seems strangely prescient.

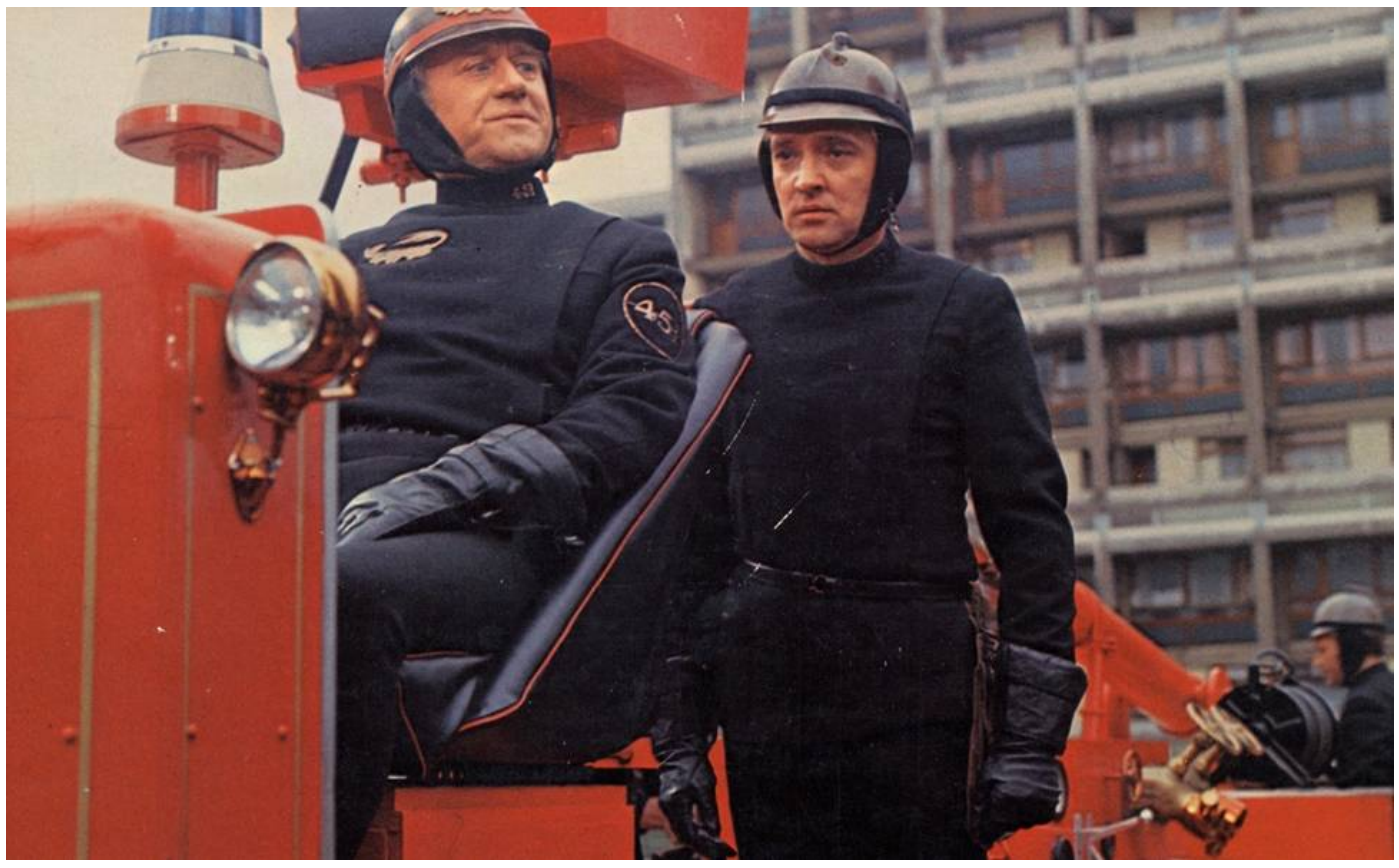

Figure 1. The characters of Beatty and Montag in François Truffaut's film of Fahrenheit 451, 1966 [2].

Stephen Apkon, author of The Age of the Image, remarked that in 2011 there were more iPhones born into the world than babies, and there are now more videos uploaded to YouTube per month than all the content created by the three major TV networks of the US since their inception more than 60 years ago [4]. At the very least, as James Elkins began in his Visual Literacy book, "A tremendous force of rhetoric has been brought to bear on the notion that ours is a predominantly visual culture" (vii, 2008), [5].

Does our present journey through multiplying images foreshadow a destination with all pictures and no writing? Let's imagine that our image-saturated world were to become more so, to the point where the written word disappeared, as in Truffaut's Fahrenheit 451, and all we had to communicate with each other, outside of speech, were pictures. For my purposes here I'm more interested in the effects and less interested in the cause of the rise of pictures and eradication of writing, but Fahrenheit 451's predictions seem to parallel the developments we are currently witnessing. It is a fascist state of sorts, but a strange one indeed in that it is hell-bent on not upsetting anyone. In Bradbury's original telling of the story, this future came about through the gradual abridging of communication. The captain of the firemen (the ironic name given to the occupation of starting fires rather than putting them out) Beatty, explains to his subordinate, Montag, the book's antihero that:

"Classics [were] cut to fit fifteen-minute radio shows, then cut again to fill a two-minute book column, winding up at last as a ten-or twelve-line dictionary resume [...] Why, How, Who, What, Where, Eh? Uh! Bang! Smack! Wallop, Bing, Bong, Boom! Digest-digests, digest-digest-digests. Politics? One column, two sentences, a headline! Then, in mid-air, all vanishes! [...] It didn't come from the Government down. There was no dictum, no declaration, no censorship, to start with, no! Technology, mass exploitation, and minority pressure carried the trick" (1953), [3].

Bradbury's original story seems to suggest this trajectory continued until all writing evaporated. So let's go with that $n$th degree sequence of events, to ask what the possibilities of picture-only communication might be. It's a useful experiment for communicators because rarely do we ask what 
pictures alone are capable of, and there's a range of assumptions about their limits, not helped by an education system that doesn't encourage exploration in this direction.

What would happen to your daily activities if you woke up one morning and the writing was gone? Of course, none of us academics could survive for a second! We depend on email, Google Scholar searches and other computer-bound, text-heavy activities. But doors are already opening in these contexts: for example, it has been possible for some years to upload a picture as a search "term" to find its origins. Who knows what future opportunities these doors might open upon? What about more pressing concerns outside of academia such as water and food? -Let's assume we still have running water. The hot and cold taps don't need the H \& C (or C \& F in Italian). Red and blue will do just fine to indicate, with unusually high iconicity in our world of symbols, heat and cold. What about obtaining foods? There'd be no text on our labels. We should probably all buy our food from around the edge of the supermarket: the stuff that isn't in tins and boxes. And packaging can sport pictures of what the ingredients once looked like anyway. An award winning Japanese packaging design from the 1970s (Figure 2) already went so far as to remove writing. And when was the last time you looked carefully at the cash register to read the amount rung up by the clerk? Wave your credit card and be on your way! Getting to and from this purchase in a vehicle? The gauges in your car display a spatial relationship you long ago got used to without having to read and intellectualise the numbers. The same goes for telling the time to get to those important meetings. At least on the face of it, it's not inconceivable to have an ordinary day without writing.
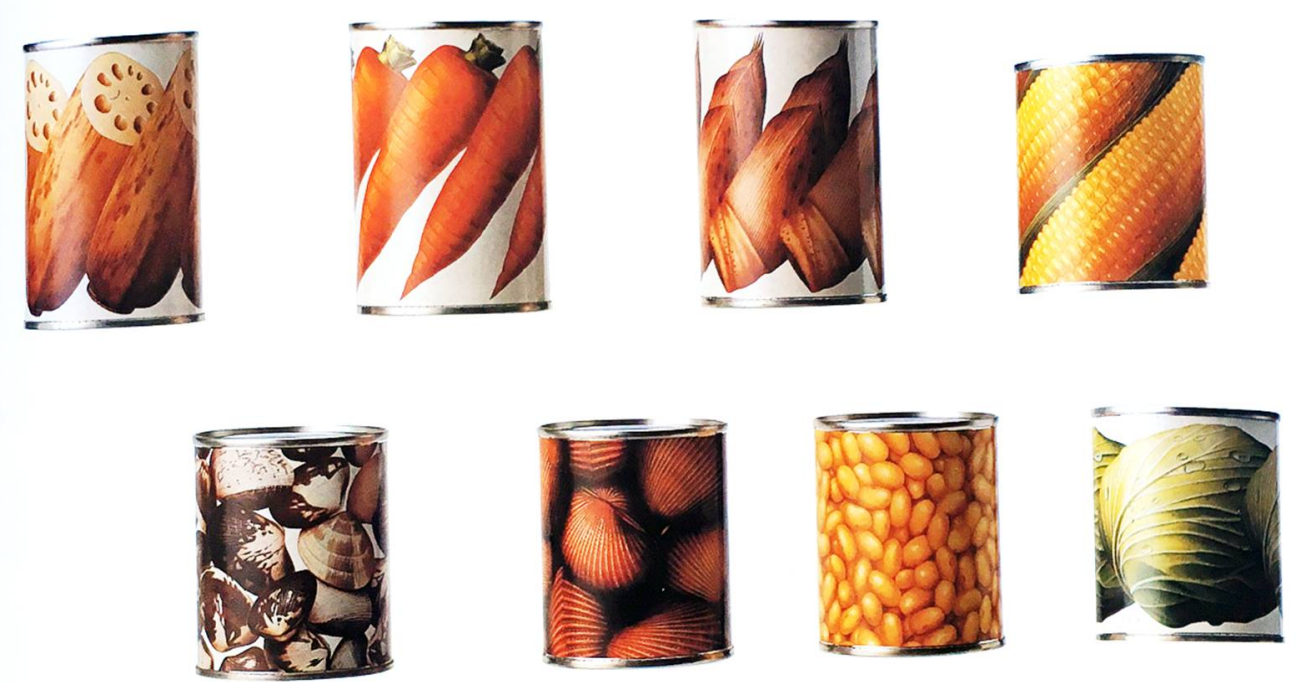

Figure 2. Shin Matsunaga, packaging for Kibun, 1977.

In contemporary contexts, and staying with getting from A to B, the removal of writing from a traffic environment can even make it safer. As Charles Landry of 'creative cities' reports, one of London's busiest roads and shopping streets, Kensington High Street, used to have a complicated and unsightly clutter of signs, and accidents were frequent. The deputy mayor decided to get rid of all the signs and guardrails. Officials were worried. Wouldn't accidents increase? Accidents decreased because drivers now pay attention to pedestrians and do not assume they control the roads, and pedestrians take more care too. This case makes clear that at least some of our assumptions, not least about the necessity of writing, might be ill-founded.

\section{Future Predictions, Past Possibilities}

Apart from entertainment, what would be the point of imagining a future of communicating without writing? Outside the realms of literature and film a serious project already envisions such a future, as a visual communication task with the most deliberate intent. The document "Expert Judgment on Markers to Deter Inadvertent Human Intrusion into the Waste Isolation Pilot Plant" (or 
WIPP for short), as its title suggests, describes how experts were gathered to make recommendations on how to stop people opening up a radioactive waste store [6]. The problem was, and still is, the WIPP, because of the half-life of the radioactive waste it stores, will be deadly 10,000 years hence. So, a team, including experts from the fields of anthropology, archaeology, architecture, astronomy, communications, design, engineering, geology/geophysics, linguistics, materials science, psychology, semiotics, and sociology were charged with the task of warning people, 10,000 years into the future, about that radiation hazard.

This project from 1993, although it doesn't assume writing will disappear, has to assume that writing has disappeared; at least writing as we know it. In the same way that hieroglyphics were only a few thousand years old when rediscovered, but their meanings were only guessed at until the decrypting of their code through the Rosetta Stone, the WIPP experts had to assume that any writing system available today may be meaningless if encountered by humans in the distant future. Since symbols of any kind rely upon shared understanding between two or more people, responses from the teams charged with proposing a solution to this unusual communications problem veer away from the symbolic towards the iconic and the synaesthetic. Material considerations also become germane; what matter will stand the test of time? The medium of these messages matters very much.

It takes an interesting thought experiment like this to reveal just how deep-rooted are the assumptions around visual communication. Of course, it's not impossible to picture a world without writing as Truffaut has done. It's not so long ago in human history that we stepped out of that state. But that world we came from has also been painted as a primitive one. Pictures that survived from then are viewed through our present contextual lenses as, at best, merely representing what cave-people saw in their environment, and at worst assumed to embody superstition and fear; containing a child-like view of the universe. This view has not been helped in western history by hundreds of years of monotheism and its vested interest in framing earlier belief systems as perverse. We know that writing systems have not always existed for mankind. For the vast majority of human history, we thrived without them. Some cultures never invented writing at all. But every culture had pictures, had sculpture, had people who saw faces in the edge of a cloud or figures dancing in the flames.

In Against the Grain: A deep history of the earliest states, James C Scott, positions writing and fire as technologies from opposing walks of life. Agriculture, especially the organized growing of cereal crops, meant leaving behind the controlled burning of the hunter-gatherer and led to the invention of writing as a means of recording farming inventory. Writing is completely bound up with accounting for production, for tax collecting and distribution, with specialization into occupations: the beginnings of the organized state. Scott maintains that for 500 years after its invention writing was used only for lists, lists and more lists [7].

\section{Deliberate Communication with Pictures: A Science Fiction?}

However, since writing emerged from the need to account, with precision, for what was grown, bought and sold, it makes sense to ask of our text-free future: What about deliberate communication? Apart from making effective warnings about radiation, what of the unambiguous communications we need to share? It's unlikely the world could support nor would want eight billion huntergatherers, so, if we are to continue in the vein of being civilized, that is living closely together, with specialized roles, we need to account for transactions of labour, goods and services, and we need to give effective instruction to educate each new generation. We need to communicate some things that, unlike other pictorial modes in modern visual art, are not open to interpretation. Could a future of pictures-only give us the deliberate communication we'd need for these exchanges or is that also science fiction? Surely pictures are too vague? Certainly, Timothy Donaldson, author of "Shapes for Sounds: why alphabets look like they do", thinks so. He writes, "images always need to be explained with supporting text. More often the real communicating is being done by the words", and he is happy to point out that "Every text that advances opinions that we are moving away from word-based communication usually does it with a lot of words" [8] (p. 9, 2008). By writing this down I risk strengthening his case, but I will persevere. 
In Truffaut's film version of Fahrenheit 451, even the newspapers, shown here at Figure 3, are in a picture-only format [2]. As a comics artist this was one of the aspects of the film's production design that really caught my attention. "Fake news" notwithstanding, a reader likes to think that the newspaper can explain clearly and deliberately the issues of the day. As a comics maker I know that producing the news as a comic on a daily basis would take an army of creators. But why not? Apart from the daunting logistics, would pictures be too vague or ambiguous? Or might it be no more than a popular misconception that pictures are more vague than writing? We hardly have education systems that help explore whether this is fact or not.

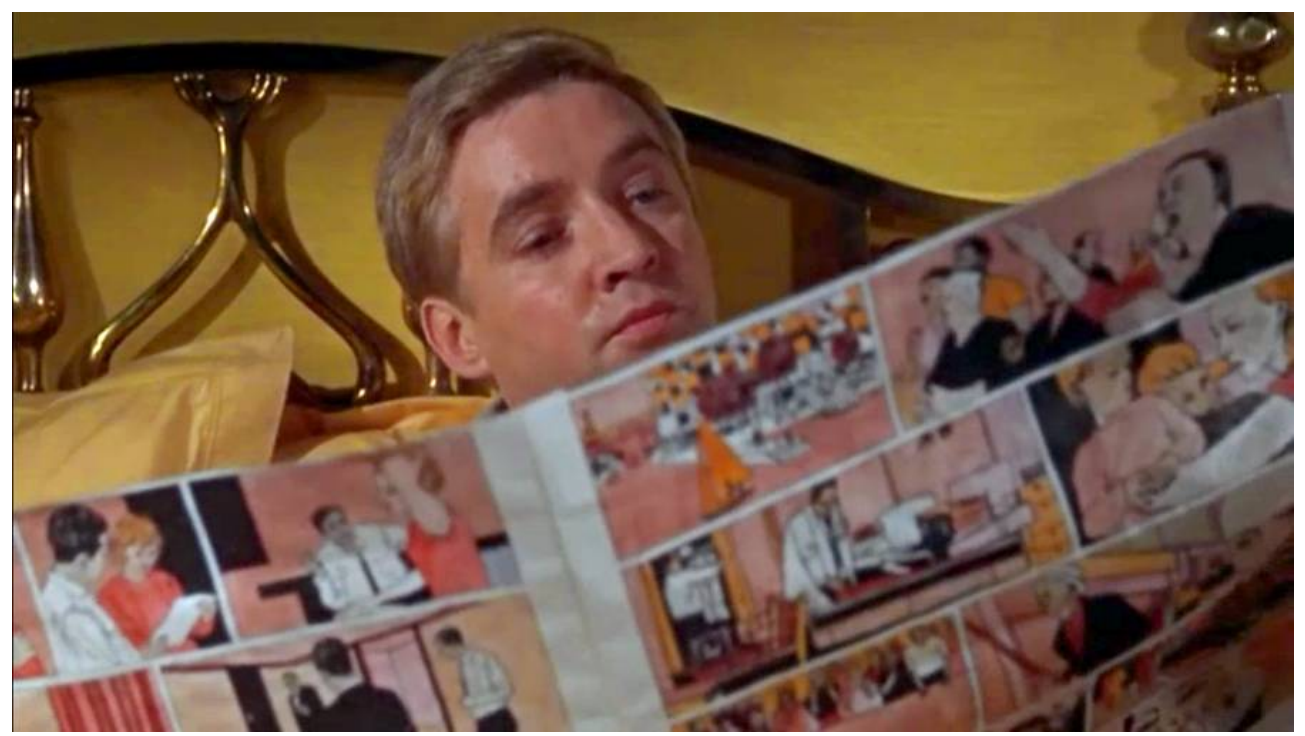

Figure 3. The newspaper in Fahrenheit 451 communicates through pictures alone [2].

In Anglophone societies at least, as early visual literacy advocates Balchin and Coleman observed, we are "weaned off" pictures as we "progress" as readers [9]. The major assumption to overcome as I see it is the notion that the dependability of words somehow anchors the waywardness of pictures. I see this in the writing even of theorists that really should know better since their field of study is visual communication of some kind (Donaldson on the history of letter forms, Postema on comics [10]); that words always disambiguate pictures. However, as Barnard \& Johnson demonstrated quite simply (2005), pictures can disambiguate words (Figure 4).

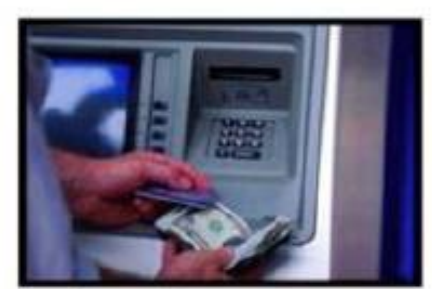

bank

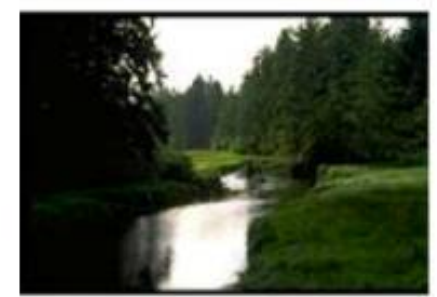

bank:

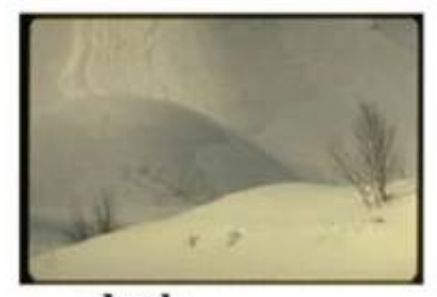

bank

Figure 4. The common assumption is that words disambiguate pictures, but the reverse can also be as true [11].

Indeed, we need not look far for deliberate pictorial communication, even in our present age. Ikea instructions for turning flat packs into furniture, or airline safety cards are neither of them open to interpretation. These are what Umberto Eco would describe as 'closed texts'. The sequence of pictures, the repetition of certain forms, and the carefully stepped changes in other forms in these objective comic strips, certainly aids the cause of unambiguous communication, just as words benefit from the context of the sentences and paragraphs they are couched in. 
That accounts visual instructions, but it's even possible to find contemporary examples of visual argument. The $i$ Raq illustration at Figure 5 by Forkscrew makes its case through reference to two precedent pictures, and, as any good argument should, offers evidence to support the point-of-view of its creators. The poster uses the infamous photograph of the torture of Iraqi Professor Ali Shalah as one reference. The silhouette is an accurate tracing of the photograph, and the photograph is (and was, in a very legal sense) evidence of the torture of the professor by U.S. military staff at the Abu Ghraib prison. The other clear reference the iRaq poster makes through its saturated, chromatic colour and strong black silhouette is to the precedent contained in the famous Apple iPod campaign designed by Susan Alinsangan et al (Segall, 2012). Its typography and grenade logo echo the other elements of that visual quote. Advertisers have long used visual expression to carry propositions. The iRaq poster then proposes an uneasy proximity between the unproblematic iPod ads and the photograph of torture. It is difficult not to see this as drawing a direct connection between U.S. corporate interests and military intervention to make its visual argument.
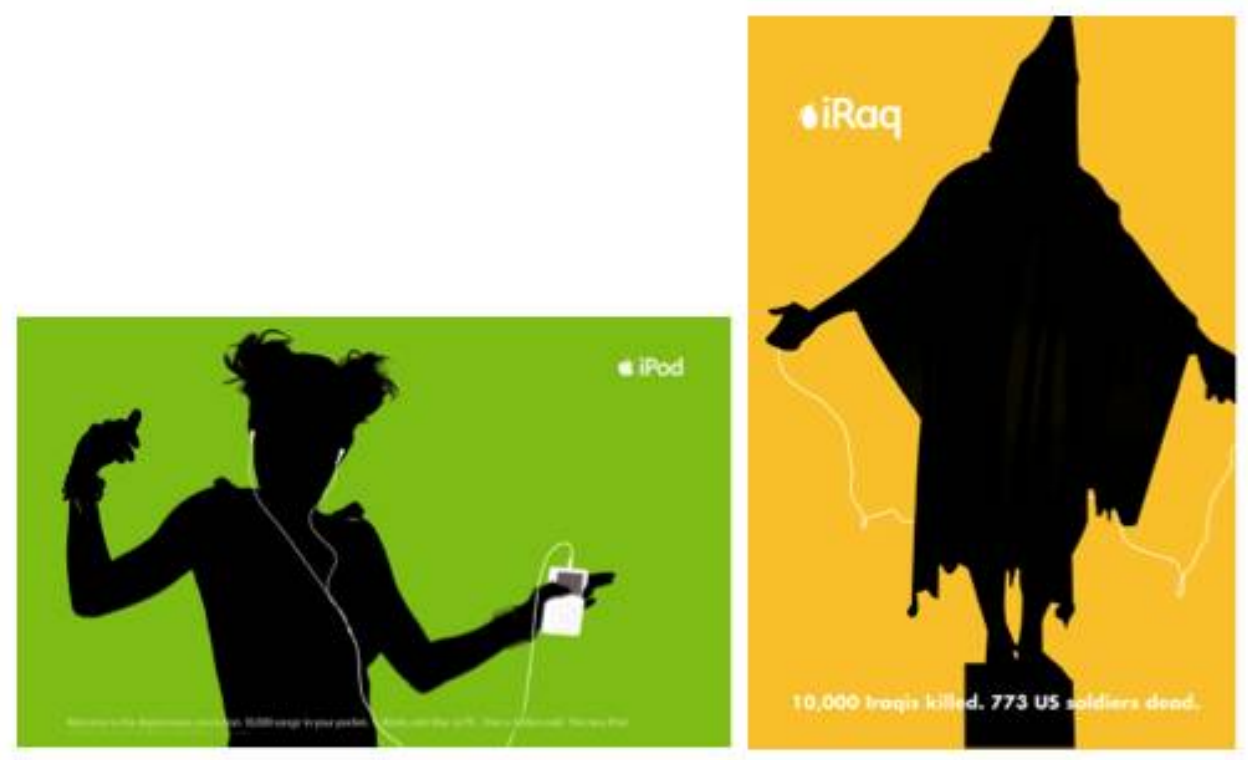

Figure 5. Advertisement and parody. (left) Susan Alinsangan, Lee Clow, James Vincent, Chiat/Day. iPod advertisement campaign (2003); (right) Forkscrew. iRaq [Abu Ghraib Prisoner], silkscreen (2004).

Again, taking matters to the $n$th degree, where do arguments end up if a resolution is not easily found? Sometimes in a court of law. Perhaps in the future, if complex human interactions requiring contractual legal agreements could be made visual we might have absolute confirmation that writing could be superceded by pictures even in the most exacting of contexts. That future may already be arriving. As I write this keynote, preparations are almost complete in my home town of Perth, Western Australia, for the world's first conference on comics as legal contracts (www.comicbookcontracts.com). An example document from this new movement is shown at Figure 6; a contract between a farmer and fruit-picking labourer. At first the pictorial translation of foreign worker contracts may seem patronizing of those workers, but viewed from another angle, it could be said that it's difficult for anyone to be literate in legalese; a different use of language than the everyday and a culture unto itself. Even the legal profession sometimes struggles with the letter of the law: How often do we hear of decisions made, even by learned judges, being overturned? To be sure none of these comics contracts has been legally challenged as yet, but it may well be the reason none has been tested in court is that these visually expressed agreements are clearer to all parties than textual agreements [12]). 


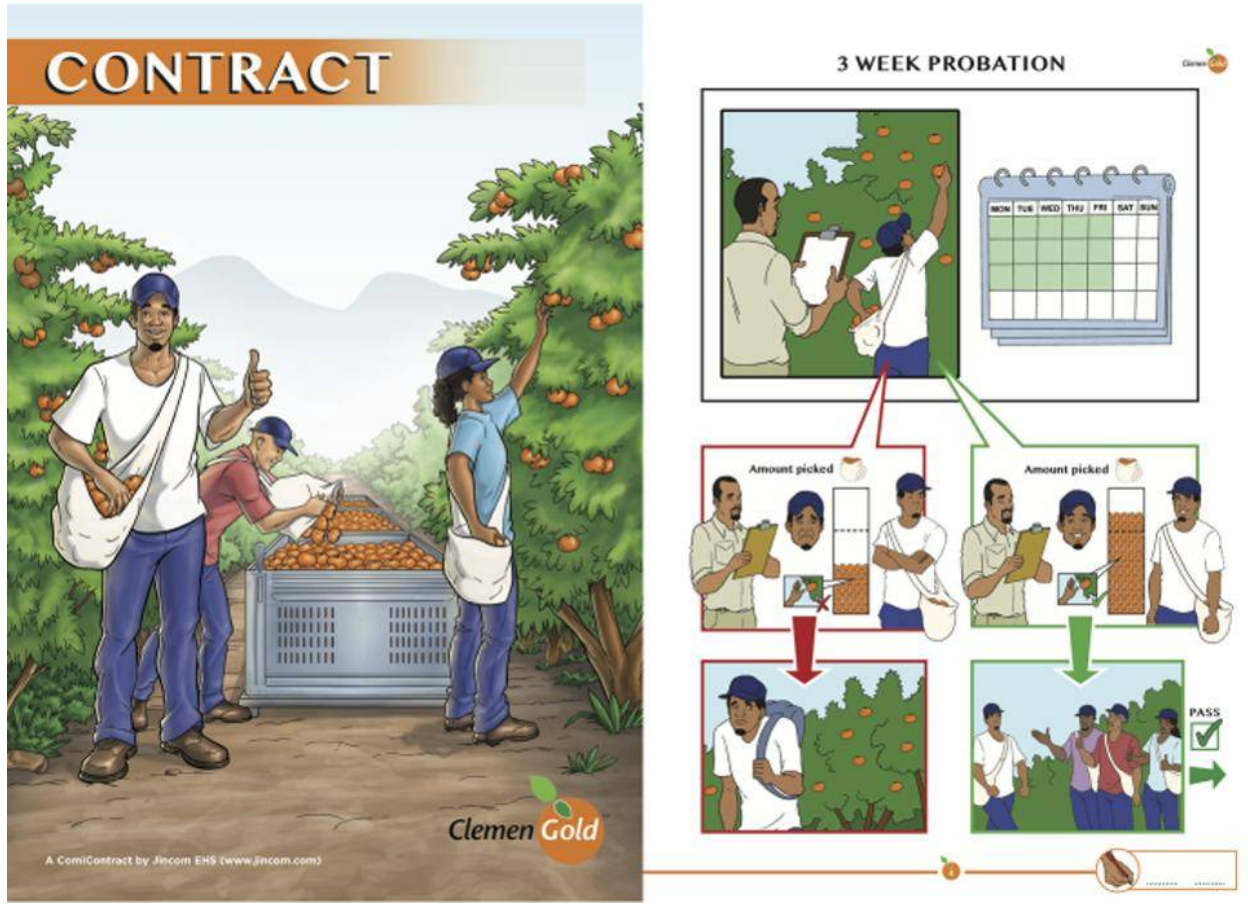

Figure 6. Work contract drafted in comics form by Comics Contracts and Jincom Publishing, South Africa.

These comics contracts are startling because of their largely pictorial composition. However, it must be recognized that, so far, text still survives in these documents, albeit in a much-diminished role. Perhaps the future is most likely to witness the further compression of writing, not its total eradication. Yes, pictures can disambiguate words and vice versa, but it is likely the co-presence of the two modes that makes for clearest communication.

\section{Sci-Fi Curricula}

What if we were to head to a future where we communicated more and more through pictures and less and less through the written word? How would one be trained to be a productive member of such a world? As Anne Bamford noted in her Visual Literacy White Paper (2003): there can be no dictionary of images since it would be as limitless as the imagination and graphic skills of humanity [13].

If the search for such a visual vocabulary is a 'wild goose chase' can we approach the problem another way? The key to providing a big picture view might be to push past these assumptions about the alleged vagueness and primitiveness of pictures compared with the supposed exactitude and sophistication of writing. But we should, above all, question the assumptions about pictures sustained in our own visual communication fields. Early visual literacy theorists recommended the camera as the tool through which children could attain visual literacy. The assumption that the photographic or filmic image is the one to become expert in continues today with Stephen Apkon's The Age of the Image [4] which, perhaps because the most prevalent kind of image on the Web is the photographic, makes no special mention of any other kind of picture. Yes, cameras are wonderful tools, but provide us with an extremely narrow bandwidth of visual communication possibilities. They're about recording the visual, not making visual that which is not, as if capturing the already visible were all that mattered. An understanding and a competence in both 'reading' and 'writing' pictures is necessary for growing visual literacy. Even in education focusing on drawing, the pursuit of high visual realism has for too long been held up as the ideal.

In my field of graphic design there has always been a separation between words, which are usually supplied by the client, and typography, the inaudible 'voice' that the designer gives to the client's words. If we borrow W.J.T Mitchell's separation of image from picture maybe we can do something similar for non-written communication in order to dodge Bamford's impossible 
dictionary: for our visual choices we need not concern ourselves unduly with image; with what is shown, but rather with pictures; how something is shown [13].

The Realism continuum (Figure 7) is a blunt yet effective instrument that makes this distinction more clear. Any image (whether seen in the real world with the eyes, or imagined in the mind) can be captured with varying degrees of fidelity in a picture, with the photograph at the very realistic end of the scale and the chirograph, or hand-made picture supplying all the other possibilities of depiction. The continuum very roughly parallels Peirce's semiotics of Icon I index | symbol but sidesteps their association with linguistics and writing, while also reminding us that a picture's function is a matter of degree and context.
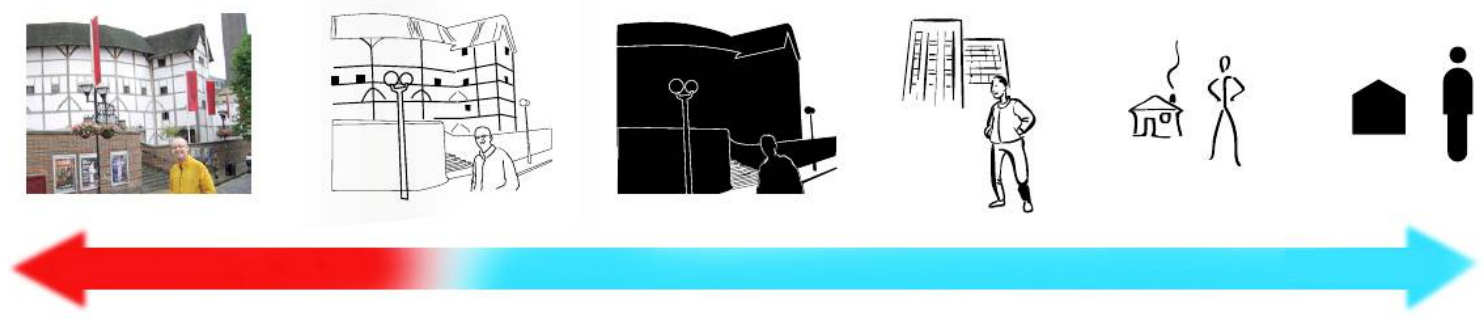

Figure 7. Realism continuum may show an array of pictures of different fidelity which bear a relationship to the same image. Pictures may range from 'Concrete to Abstract', 'Specific to Universal', from 'Identification to Categorization' among other visual communication tasks.

Furthermore, the continuum is an effective way to demonstrate that pictures have a role to play in deliberate communication, and that some kinds of pictures (of higher fidelity) are better at helping us identify specific examples within a class of objects and others (of lower fidelity) are better at helping us categorise things into classes.

Pictures tend away from the symbolic to the indexical and the iconic, while writing - at least with alphabets-is always symbolic. Furthermore, writing consists of symbols of symbols: visible marks which represent sounds which represent aspects of our experience. Pictures can form a language too, but of a different kind. Andrew Large in his The Language Makers distinguishes between a priori and a posteriori languages, and recounts the hundreds of efforts, particularly since the 17th Century, to manufacture languages - for example, Esperanto-auxiliary to those that have arisen more organically. Only the latter, the a posteriori languages, have been made to codify sounds. A priori languages are those constructed to communicate philosophical categories in order to categorise human knowledge [14]. Not all of these were written with existing alphabets. Knowledge of these differences could aid in the construction of a future picture language.

With the realism continuum in mind, some science-fiction contexts provide effective strategies around which to develop visual communication curricula. The abovementioned WIPP project is an introductory problem for my first year design students. In two hours, without any knowledge of the original design solutions, they must discuss the problem among themselves, as if they were the team of experts, then sketch and construct a potential solution. No text may be used, nor may radiation symbols symbols be used, since these are also specific to our contemporary experience. Typically, after some excited discussion, students arrive at strategies employing highly iconic (as opposed to symbolic) forms and synaesthetic forms (featuring jagged edges and sharp points), made as prototype statues or bas-relief carvings. Their responses (Figure 8), tested by other students from outside the class, reflect closely those reported from the two teams of experts contracted in the WIPP proposal. 

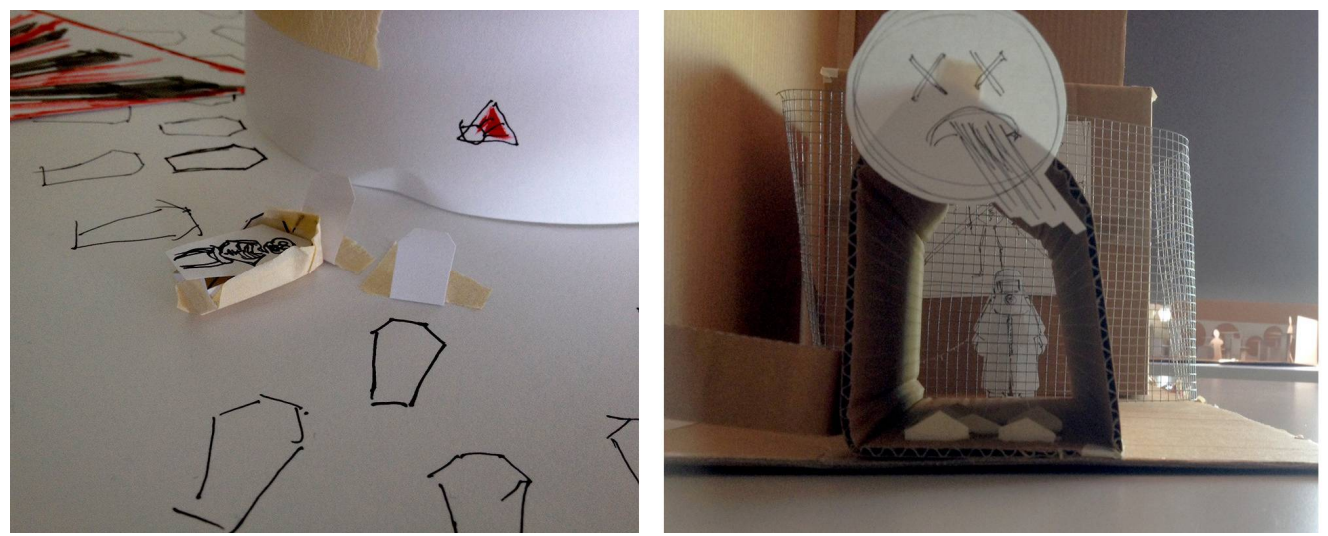

Figure 8. Student responses to in-class exercise duplicating the WIPP brief.

Another science-fiction problem, derived from NASA's 1977 Voyager spacecraft project, is put to our visual communication students. Aboard that spacecraft NASA placed the 'Golden Record' of life on earth, depicted through photographs and diagrams, as well as music and spoken word recordings. The original messages are problematic as these were not developed by visual communication specialists: the images, as with the spoken word recordings, require a knowledge of Earth languages to be understood! Students are asked to choose one of the images and explain its concepts in a way that avoids established symbolic language, assuming of their hypothetical alien audience nothing more than the faculties of sight, manipulation and curiosity. Sample responses are shown at Figures 9 and 10. As with the WIPP project, for educational purposes these projects are not about communing with the future or with aliens but about closely interrogating assumptions of a message's audience, and choosing appropriate levels of realism and abstraction, of iconicity and symbolism to convey that message.
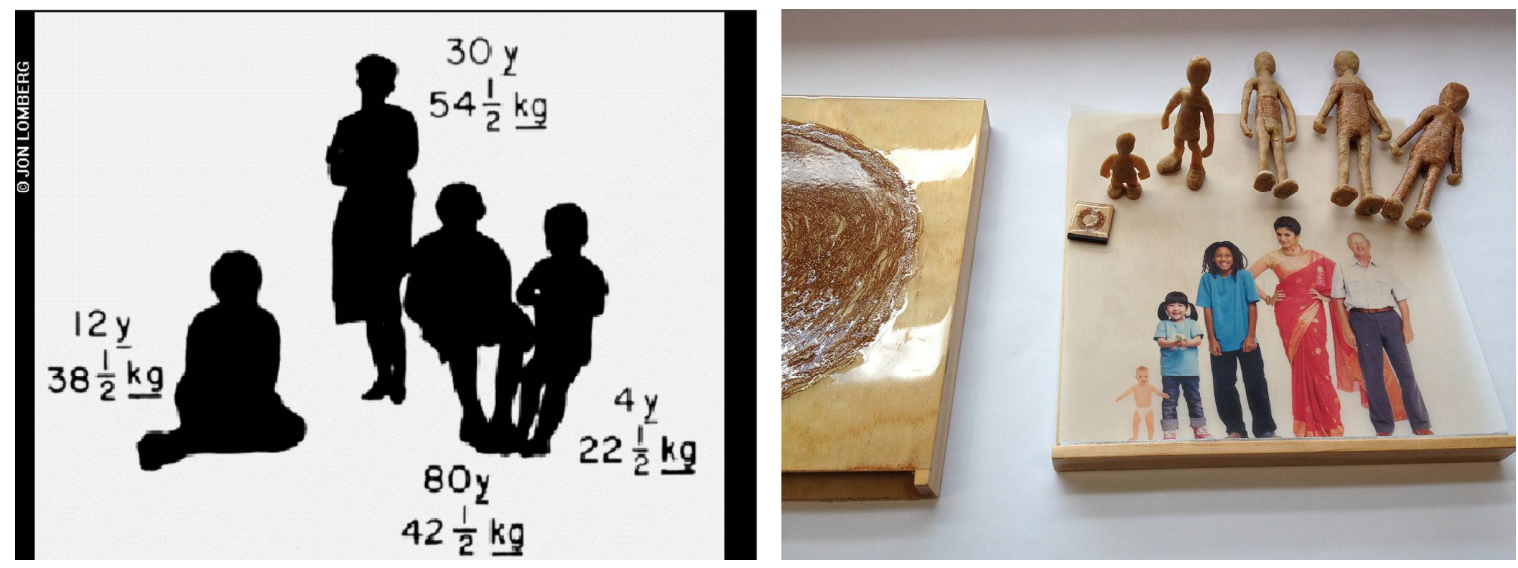

Figure 9. Shows a student redesign (right) of one of the NASA Golden Record messages about (left) human growth. The redesign features proportionally weighted and scaled human figures rather than numerical symbols. The proportions are based on the record itself-something the students understood could be used by the aliens as a reliable measure of scale.

WIPP and the Golden Record projects both present a science fiction of illiteracy, where communication must be achieved through figural forms. But what about those that can't draw? Wouldn't such a future be terribly onerous and exclusionary? One of the reasons for this thought experiment, this future without writing, might be to examine what it means to be ingraphicate (a word derived from Balchin and Coleman's 1966 call for graphicacy [9]). A society that puts emphasis on reading and writing may not be fully aware of what it means to communicate with pictures. As Gombrich pointed out 'The first prejudice teachers of art appreciation usually try to combat is the belief that artistic excellence is identical with photographic accuracy'. Those that say they can't draw often mean they can't draw realistically. But realism and effective communication only rarely 
overlap. Other things in human existence, which cannot be photographed or visually recorded are also true; the taste and smell and feel of things, for instance. The humunculus illustration (at Figure 11 ) is also true. It is a "graph" of human brain processing devoted to specific physical geography.
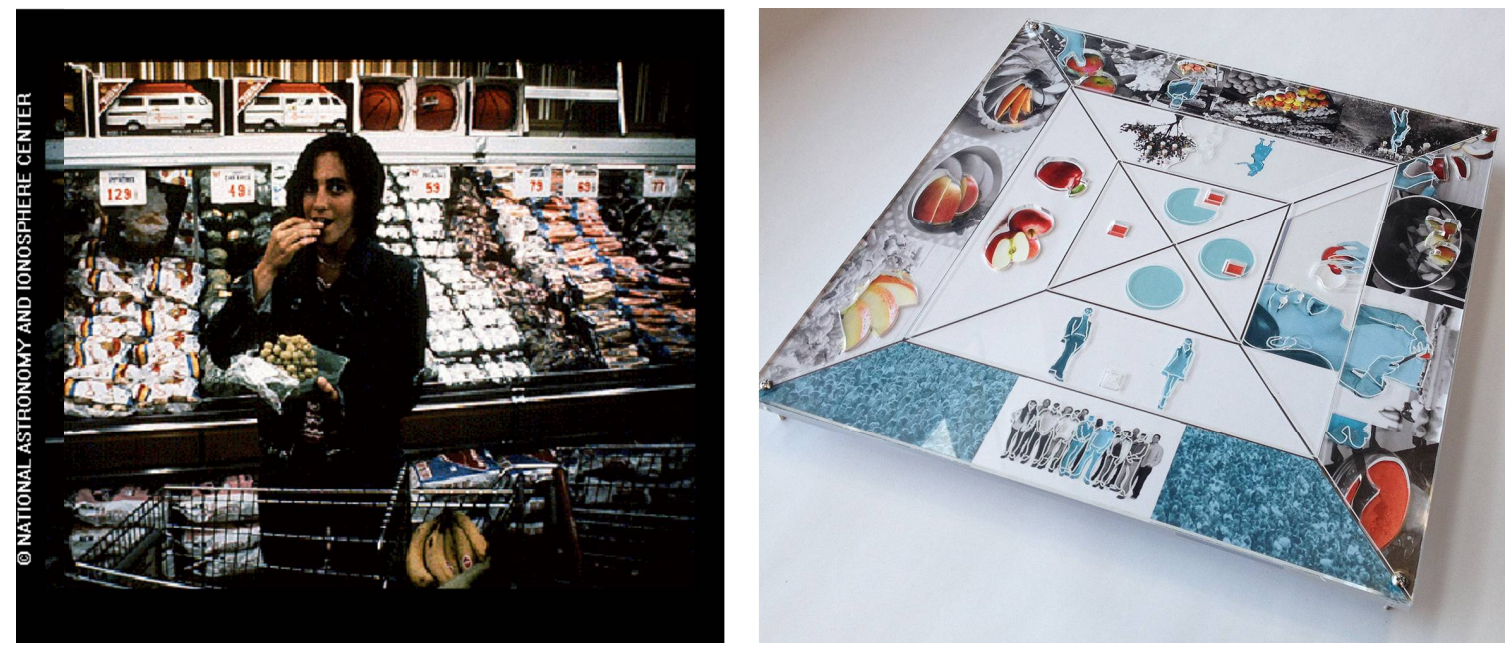

Figure 10. Shows a student redesign (right) of the original NASA image (left) about food consumption for energy. The redesign attempts to teach its audience an equivalence between the icon and the symbol for person and for food. The device assumes some gestalt laws of belonging may be universal for sentient beings, and uses the knowledge that colour trumps shape.

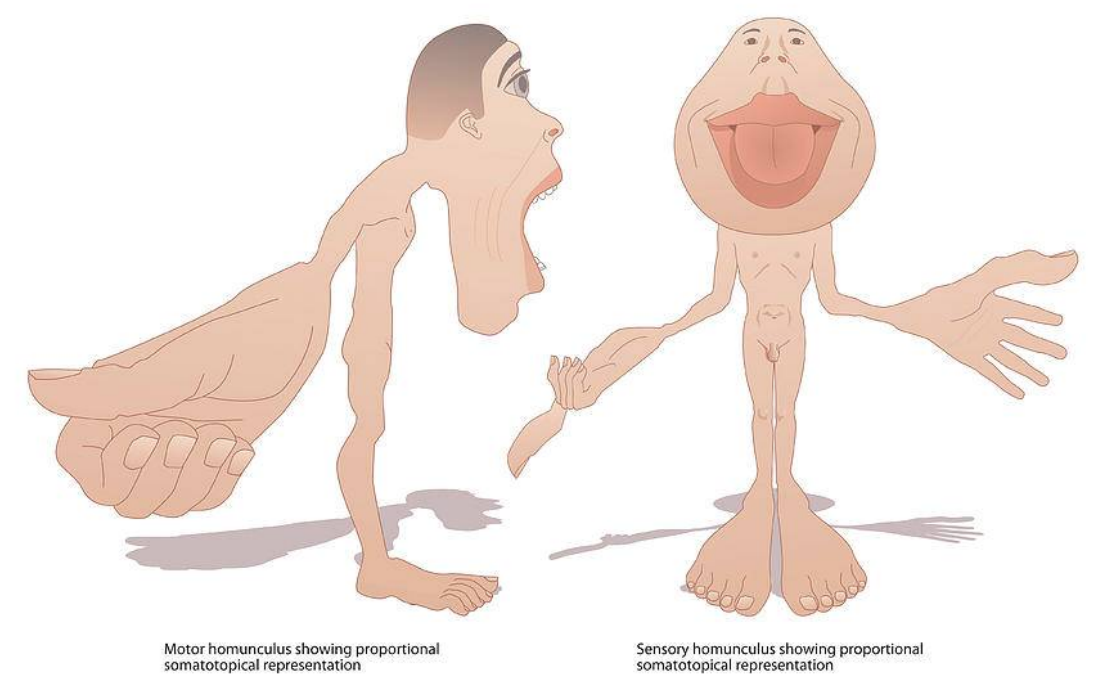

Figure 11. Peter Gardiner, Humunculus illustration graphs onto a human form the relationship between the geography of a point on the outside of the body to a point in the central nervous system.

Another science-fiction style project developed in our program encourages students to embrace their own way of drawing to make outlandish creature designs through a distortion of their own visual schemas. This exercise questions the value axiomatic art lessons such as life drawing and formulaic construction of the human form in order to purposefully develop character designs and individual style. Students find benefit in 'deliberately getting it wrong', especially with regard to expressing emotional states-drawing from what they remember and feel rather than what they see-drawing characters consistently and differentiating between characters. Style is a function of a set of choices. The workshop makes the choices overt and makes clear that the choices may be wider than students first supposed (Figure 12). 

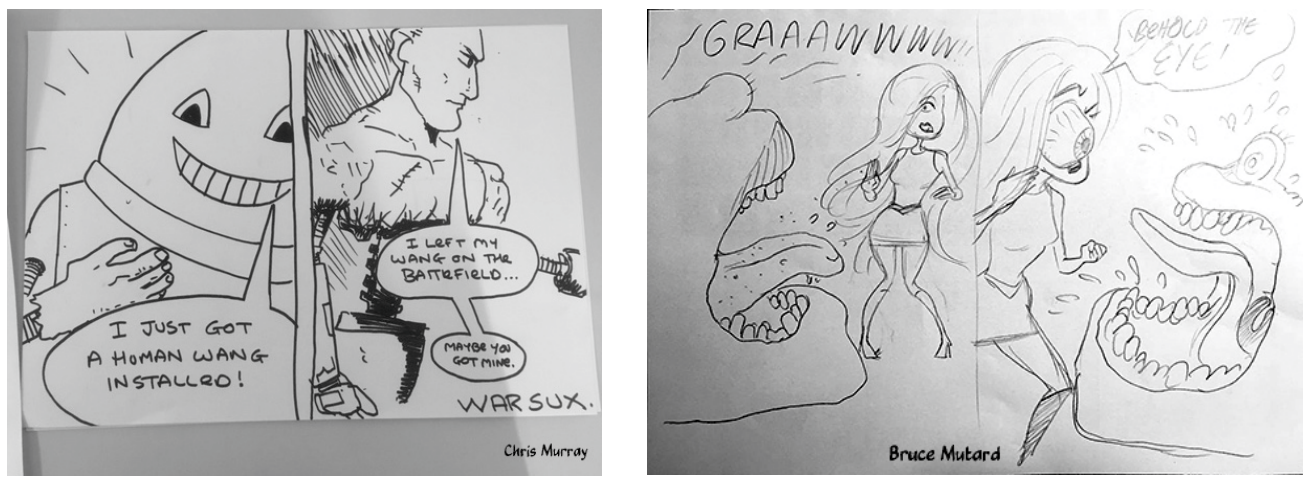

Figure 12. Samples of participant work from the science-fiction character design workshop.

A theory of depiction should look less at the idea of resemblance to the real world and more into the act of ordering existence that the artist undertakes when making a picture [15]. With the very real possibility that the more evident is some style, the more cognition we may gain about the world and particularly about others' views of it.

We're on the threshold of understanding that different pictures of the same image convey different meanings. Research into style, pattern recognition and comprehension are necessary to further break down the historical assumptions about what constitutes good depiction. We need to break the spell of visual realism, or at most to see it as one of many choices for capturing the image, and to see the schema that make pictures up as components that can be taken apart and reassembled.

\section{Conclusion: Written in the Flames}

Why carry out a thought experiment of imagining this sci-fi future? It's not really for warning our descendants about radioactive waste. Nor is it about wanting to eradicate pictures. Ironically, one of the wonders of writing is the latitude it allows the reader in imagining pictures. (Incidentally, in a meta-mirroring of Truffaut's vision of a future without writing, a more recent science-fiction film, Mad Max Fury Road, was not written at all but completely developed through drawn storyboards.)

If the future is merely about a reduction in text and an increase in pictures compared with the past, then getting good at communicating through pictures alone might make you a better communicator for such a future. My belief is that, as a result of the assumptions that have taken root around the communicative capabilities of images we don't yet know their full possibilities in deliberate communication. Imagining a science-fiction future where writing has disappeared is one way to attain that knowledge.

Truffaut's vision is not a particularly dark dystopia. As Bradbury suggested in the original text, eradicating writing was intended to keep everyone happy. James C Scott's deep history of the earliest states suggests the same: had we focused on flames and pictures rather than agriculture and writing we would be a happier species [7]! Perhaps those of us advocating for a greater emphasis on pictorial communication can work at breaking down the limiting assumptions that have surrounded pictures in western cultures, and leave it to those who come after us to fully realise those potentials: To our students and to the future!

Conflicts of Interest: The authors declare no conflict of interest.

\section{References}

1. Sander, K. Hard Drive: An Experiment in Intervisuality. Red Hook. 2012. Available online: www.bard.edu/ ccs/redhook/hard-drive-an-experiment-in-intervisuality/ (accessed on 30 August 2011).

2. Truffaut, F. Fahrenheit 451; United Kingdom: Anglo Enterprises Vineyard Film Ltd.: London, UK, 1966.

3. Bradbury, R. Fahrenheit 451; Flamingo: London, UK, 1993.

4. Apkon, S. The Age of the Image: Redefining Literacy in a World of Screens; Farrar, Straus and Giroux: New York, NY, USA, 2013. 
5. $\quad$ Elkins, J. (Ed.) Visual Literacy; Routledge: Abingdon-on-Thames, UK, 2009.

6. Trauth, K.M.; Hora, S.C.; Guzowski, R.V. Expert Judgment on Markers to Deter Inadvertent Human Intrusion into the Waste Isolation Pilot Plant (No. SAND--92-1382); Sandia National Labs.: Albuquerque, NM, USA, 1993.

7. Scott, J.C. Against the Grain: A Deep History of the Earliest States; Yale University Press: New Haven, CT, USA, 2017.

8. Donaldson, T. Shapes for Sounds; Mark Batty Publisher: New York, NY, USA, 2008.

9. Balchin, W.G.V.; Coleman, A.M. Graphicacy should be the fourth ace in the pack. Cartographica 1966, 3, $23-28$.

10. Postema, B. Narrative Structure in Comics: Making Sense of Fragments; RIT Press: New York, NY, USA, 2013.

11. Barnard, K.; Johnson, M. Word sense disambiguation with pictures. Artif. Intell. 2005, 167, 13-30.

12. Leiman, T. Where Are the Graphics: Communicating Legal Ideas Effectively Using Images and Symbols. Legal Educ. Rev. 2016, 26, 47.

13. Bamford, A. The Visual Literacy White Paper; Adobe Systems: Sydney, Australia, 2003.

14. Large, A.; Pitt, A. The Language Makers; Roy Harris: London, UK, 1988.

15. Bell, G. Depiction and Painting: A Theory and History of Art 1950-2000. Ph.D. Thesis, The University of Melbourne, Melbourne, Australia, April 2001; pp. 26-27.

(C) 2018 by the authors; Licensee MDPI, Basel, Switzerland. This article is an open access article distributed under the terms and conditions of the Creative Commons Attribution (CC BY) license (http://creativecommons.org/licenses/by/4.0/). 